\title{
Malignancy Rates in Brodalumab Clinical Studies for Psoriasis
}

\author{
Alice Gottlieb $^{1} \cdot$ Mark Lebwohl $^{1} \cdot$ Clive Liu $^{2} \cdot$ Robert J. Israel $^{3} \cdot$ Abby Jacobson $^{4}$
}

Published online: 23 March 2020

(c) The Author(s) 2020

\begin{abstract} of adults with moderate-to-severe plaque psoriasis. follow-up time-adjusted event rates per 100 patient-years (PY). (AMAGINE-2); NCT01708629 (AMAGINE-3).

\section{Key Points}

Because psoriasis is associated with an increased incidence of some malignancies such as skin cancer, we assessed the malignancy rates in multiple clinical studies of brodalumab, a fully human anti-interleukin-17 receptor A monoclonal antibody efficacious for the treatment of moderate-to-severe plaque psoriasis.

We found that brodalumab appears to have a low carcinogenic risk of malignancy on the basis of an analysis of $>8000$ patient-years of exposure.
\end{abstract}

Background Brodalumab is a fully human anti-interleukin-17 receptor A monoclonal antibody efficacious for the treatment

Objective This study summarizes malignancy rates in psoriasis clinical studies of brodalumab.

Methods Data were pooled from one phase II study and three large, multicenter, phase III randomized studies of brodalumab for the treatment of psoriasis, including two studies with randomization to brodalumab, ustekinumab, or placebo. Data from the 52-week (brodalumab and ustekinumab) and long-term (brodalumab) pools were summarized as exposure-adjusted or

Results Exposure-adjusted event rates per $100 \mathrm{PY}$ at 52 weeks were lower with brodalumab $(n=4019 ; 3446$ total PY of exposure) than with ustekinumab ( $n=613 ; 495$ total PY of exposure), including adjudicated malignancies ( 0.9 vs 2.6$)$ and Surveillance, Epidemiology, and End Results (SEER)-adjudicated malignancies (0.3 vs 0.4$)$. The exposure-adjusted event rate of adjudicated malignancies in the brodalumab group remained stable in the long-term analysis ( 0.9 [82 events]).

Conclusions Rates of malignancy among brodalumab-treated patients with psoriasis were generally low.

Trial registry ClinicalTrials.gov identifier NCT00975637; NCT01101100; NCT01708590 (AMAGINE-1); NCT01708603

Electronic supplementary material The online version of this article (https://doi.org/10.1007/s40257-020-00512-4) contains supplementary material, which is available to authorized users.

Alice Gottlieb

alice.gottlieb@mountsinai.org

1 Icahn School of Medicine at Mount Sinai, 10 Union Square East, New York, NY 10003, USA

2 Bellevue Dermatology Clinic, Bellevue, WA, USA

3 Bausch Health US, LLC, Bridgewater, NJ, USA

4 Ortho Dermatologics, Bridgewater, NJ, USA

\section{Introduction}

Psoriasis is a chronic inflammatory disease associated with increased incidence of some cancers [1], a risk that may be related to impaired immune function or predisposing therapies in patients with this disorder [2]. In a population-based study of 67,761 individuals that examined the association between the risk of incident cancers and psoriasis, patients with psoriasis were found to have an increased risk of developing malignancies such as lymphohematopoietic and pancreatic cancers, and the risk of certain cancers was elevated in patients with long-term disease history [1]. Accordingly, patients with psoriasis should be monitored and routinely screened for potential malignancies, particularly skin cancer [3].

There may be an increased risk of malignancy among patients with psoriasis compared with the general population. A systematic review showed increase risk of solid cancers in psoriasis, including respiratory tract cancer (standardized incidence ratio [SIR], 1.52), upper aerodigestive tract cancer (SIR, 3.05), urinary tract cancer (SIR, 1.31), and liver cancer (SIR, 1.90) [2]. Increased incidence of cancer in patients with psoriasis has also been linked to the use of certain immunosuppressive and potentially carcinogenic treatments, such as cyclosporine, methotrexate, and psoralen 
and ultraviolet A light therapy [3]. For example, in a 5-year cohort study of patients with psoriasis, use of the immunosuppressive therapy cyclosporine was associated with a 2 -fold greater incidence of malignancy and a 6 -fold greater incidence of nonmelanoma skin cancer (NMSC) compared with incidence in the general population [4]. In a meta-analysis of seven studies, there was a higher risk of squamous cell carcinoma in psoriasis (SIR, 5.3), which was strongly related to the use of 8-methoxypsoralen-ultraviolet-A and, potentially, cyclosporine and methotrexate [2]. This metaanalysis also showed an increased incidence of basal cell carcinoma in patients with psoriasis (SIR, 2.00) [2].

An association between use of anti-tumor necrosis factor $\alpha$ (anti-TNF $\alpha)$ agents and NMSC, especially squamous cell carcinoma, has also been reported in several immunemediated conditions. A comparison of patients receiving anti-TNF $\alpha$ therapy showed a significantly elevated risk of NMSC in those with psoriasis relative to the risk in those with rheumatoid arthritis (hazard ratio, 6.0 [95\% confidence interval 1.6-22.4]) [5]. Expert opinion recommends avoiding the use of TNF $\alpha$ inhibitors in patients who currently have malignancy or those with history of malignancy [6].

Recently developed biologic therapies for psoriasis target immune system messengers such as interleukin-17 (IL-17), and related pathways have also been identified as novel cancer targets. For example, IL-12 plays a role in antitumor immunity through activation of antitumor effectors and blocking the expansion of intratumoral regulatory $\mathrm{T}$ cells [7]. IL-12 also contributes to maintaining cancer cells in equilibrium, allowing them to persist in a dormant rather than metastatic state [8]. Consistent with this role of IL-12 in cancer surveillance, inhibition of IL-12/23p40 in a preclinical model enhanced tumor outgrowth [8]. There may be a theoretical risk of compromising cancer surveillance through mechanisms of blocking IL-12, such as with the anti-IL-12/23 p40 antibody ustekinumab. Potential malignancies are considered an event of interest for immunomodulatory biologics, and treatments for psoriasis should be assessed for any possible contribution to risk of malignancy in these patients.

Brodalumab is a fully human anti-IL-17 receptor A monoclonal antibody [9]. Across three large phase III studies of brodalumab for the treatment of moderate-to-severe plaque psoriasis, $75 \%$ improvement in psoriasis area severity index (PASI 75) response rates ranged from $83 \%$ to $86 \%$ in patients receiving brodalumab $210 \mathrm{mg}$ every 2 weeks (Q2W) compared with $3 \%$ to $8 \%$ in those receiving placebo [10, 11]. Brodalumab is a targeted immunomodulatory agent and is not expected to be broadly immunosuppressive [12, 13]. A network meta-analysis of 109 studies of treatments for chronic plaque psoriasis (which included three studies of brodalumab versus placebo and two studies of brodalumab versus the active comparator ustekinumab and placebo) did not find evidence of increased risk of serious adverse events (AEs) with brodalumab [14]. However, the long-term effect of brodalumab on risk of malignancies remains unknown. The objective of this analysis was to summarize malignancy rates in clinical studies of brodalumab for the treatment of moderate-to-severe plaque psoriasis.

\section{Methods}

\subsection{Study Design and Treatments}

Data from a 12-week phase II study (NCT00975637) [15], its open-label extension (NCT01101100; cut-off date: June 16, 2014) [16], and three randomized, multicenter, 52-week, phase III studies (AMAGINE-1, NCT01708590 [11]; AMAGINE-2, NCT01708603; and AMAGINE-3, NCT01708629 [10]) were pooled. The methodologies of these studies have previously been described, and the AMAGINE-1 and AMAGINE-2/-3 study designs are included as Supplementary Material (Electronic Supplementary Material 1) $[10,11,15,16]$. Briefly, each study enrolled adults $\geq 18$ years of age with plaque psoriasis and PASI $\geq 12$. Use of most systemic psoriasis treatments including corticosteroids, phototherapy, methotrexate, and cyclosporine within 14-28 days before the first dose of study drug was an exclusion criteria in the phase III psoriasis trials (details in Electronic Supplementary Material 2).

Each study was placebo controlled for the first 12 weeks, and AMAGINE-2 and -3 also included ustekinumab as an active comparator up to week 52. Treatment changes were incorporated into the design of each study; therefore, patients had exposure to different study therapies (described briefly below) and experienced different durations of treatment with those therapies. Patients with active malignancy or history of malignancy within 5 years (except for treated or cured cutaneous squamous or basal cell carcinoma, in situ cervical cancer, or in situ breast ductal carcinoma) were excluded from the phase III clinical program.

In the initial 12-week period of the phase II study, brodalumab was administered at dosages of 70,140, or $210 \mathrm{mg}$ Q2W, with an additional dose at week 1, or at a dosage of $280 \mathrm{mg}$ Q4W. During the open-label extension (up to data cutoff at week 192), patients received brodalumab $210 \mathrm{mg}$ Q2W, except some patients with body weight $\leq 100 \mathrm{~kg}$ had doses decreased to $140 \mathrm{mg}$ Q2W per a protocol amendment. In AMAGINE-1, patients were assigned to brodalumab 140 or $210 \mathrm{mg}$ Q2W (with an additional dose at week 1), which persisted through the termination of the open-label extension at week 266, except for certain patients who received three weekly doses of brodalumab 140 or $210 \mathrm{mg}$ during retreatment after withdrawal and then returned to the Q2W treatment interval. In AMAGINE-2 and -3, patients were 
assigned to brodalumab 140 or $210 \mathrm{mg}$ Q2W (with an additional dose at week 1), which persisted through week 12 . From week 12 to week 266, patients assigned to brodalumab received brodalumab $140 \mathrm{mg}$ Q2W, Q4W, or Q8W or brodalumab 210 mg Q2W. In AMAGINE-2 and -3, ustekinumab was administered according to the label at $45 \mathrm{mg}$ in patients with body weight $\leq 100 \mathrm{~kg}$ and $90 \mathrm{mg}$ in patients with body weight $>100 \mathrm{~kg}$ and was given on day 1 , week 4 , and every 12 weeks thereafter through week 52 .

\subsection{Assessments}

All AEs reported in the neoplasms benign, malignant, and unspecified (including cysts and polyps) System Organ Class were medically reviewed in a blinded manner by study staff, and confirmed malignancies were categorized as adjudicated malignancies. Malignancies were further categorized as Surveillance, Epidemiology, and End Results (SEER)-adjudicated malignancies [17] if they corresponded to malignancies included in SEER reporting. The category of SEER-adjudicated malignancies excluded basal cell carcinoma and squamous cell carcinoma of the skin, in situ cancers (except for urinary bladder), benign neoplasms, and recurrent tumors. Adjudicated malignancies were also separately classified as NMSCs.

\subsection{Statistical Analyses}

Baseline demographics and disease characteristics by treatment group in the initial 12-week studies (Table 1) were summarized as mean (range) for continuous variables and number of patients (\%) for categorial variables. Data from the 12-week induction period (placebo, ustekinumab, and brodalumab), 52-week extensions (brodalumab and ustekinumab), and long-term pool (brodalumab) were summarized. The long-term pool included data collected from the phase II and III studies until their open-label extensions were terminated at 192 or 266 weeks. The all-brodalumab group included all patients who received one or more doses of brodalumab. At week 12 and week 52, data are also shown for patients who received brodalumab $210 \mathrm{mg}$ Q2W. An exploratory analysis of malignancy events occurring among patients with a history of malignancy in the phase III studies was also conducted.

Rates of malignancy events were calculated as exposureadjusted or follow-up time-adjusted event rates per 100 patient-years (PY). Exposure-adjusted event rates, which exclude gaps or interruptions in treatment, were calculated as the number of events/total PY of exposure $\times 100$. Followup observation time included gaps or interruptions in treatment and post-treatment follow-up beyond the exposure

Table 1 Baseline demographics and disease characteristics by treatment group in the initial 12-week studies

\begin{tabular}{|c|c|c|c|c|}
\hline & $\begin{array}{l}\text { Placebo } \\
(n=879)\end{array}$ & $\begin{array}{l}\text { Ustekinumab } \\
(n=613)\end{array}$ & $\begin{array}{l}\text { Brodalumab } \\
210 \text { mg Q2W } \\
(n=1496)\end{array}$ & $\begin{array}{l}\text { All brodalumab } \\
(n=3066)^{\mathrm{a}}\end{array}$ \\
\hline Female, $n(\%)$ & $272(30.9)$ & $196(32.0)$ & $459(30.7)$ & $942(30.7)$ \\
\hline Age, mean (range), years & $44.6(18-86)$ & $45.1(18-75)$ & $45.0(18-75)$ & $44.8(18-75)$ \\
\hline \multicolumn{5}{|l|}{ Race, $n(\%)$} \\
\hline White & 799 (90.9) & $551(89.9)$ & $1351(90.3)$ & $2775(90.5)$ \\
\hline Asian & $29(3.3)$ & $24(3.9)$ & $51(3.4)$ & $116(3.8)$ \\
\hline Black & $29(3.3)$ & $20(3.3)$ & $40(2.7)$ & $85(2.8)$ \\
\hline Native Hawaiian/Pacific Islander & $3(0.3)$ & $1(0.2)$ & $10(0.7)$ & $18(0.6)$ \\
\hline American Indian/Alaska Native & $2(0.2)$ & $2(0.3)$ & $8(0.5)$ & $16(0.5)$ \\
\hline Other/unknown & $17(1.9)$ & $15(2.4)$ & $36(2.4)$ & $56(1.8)$ \\
\hline Psoriasis duration, mean (range), years & $18.5(1-67)$ & $18.5(1-57)$ & $18.6(1-65)$ & $18.4(1-66)$ \\
\hline Psoriasis area and severity index, mean (range) & $20.0(12-66)$ & $20.0(12-60)$ & $20.2(12-72)$ & $20.2(12-72)$ \\
\hline \multicolumn{5}{|l|}{ Static physician's global assessment score, $n(\%)$} \\
\hline 0 or 1 & 0 & 0 & 0 & 0 \\
\hline 2 & 0 & 0 & $2(0.1)$ & $8(0.3)$ \\
\hline 3 & $500(56.9)$ & $345(56.3)$ & $827(55.3)$ & $1789(58.3)$ \\
\hline 4 & $330(37.5)$ & $235(38.3)$ & $583(39.0)$ & $1112(36.3)$ \\
\hline 5 & $49(5.6)$ & $33(5.4)$ & $84(5.6)$ & $157(5.1)$ \\
\hline Psoriatic arthritis, $n(\%)$ & $180(20.5)$ & $114(18.6)$ & $310(20.7)$ & $654(21.3)$ \\
\hline Prior malignancy, $n(\%)$ & $18(2.0)$ & $17(2.8)$ & $34(2.3)$ & $69(2.3)$ \\
\hline
\end{tabular}

$Q 2 W$ every 2 weeks

${ }^{\mathrm{a}}$ The all-brodalumab group includes all patients who received $\geq 1$ dose of brodalumab 
period. Follow-up observation time-adjusted event rates were calculated as the number of events/total PY of followup $\times 100$.

\section{Results}

\subsection{Patient Treatment Exposure and Baseline Characteristics}

During the initial 12-week studies, 3066 patients in the all-brodalumab group had a total of 688 PY of brodalumab exposure; of these, 1496 patients received brodalumab $210 \mathrm{mg} \mathrm{Q} 2 \mathrm{~W}$. A total of 613 patients in the ustekinumab group had 140 total PY of ustekinumab exposure. At the end of 52 weeks, 4019 patients had received brodalumab for a total of 3446 PY, and total ustekinumab exposure increased to $495 \mathrm{PY}$ of exposure. In the long-term pool, 4464 patients were treated with brodalumab, of whom 1304 received brodalumab $210 \mathrm{mg}$ Q2W and had no ustekinumab exposure. In the long-term pool, there were a total of 8655 PY of exposure and a total of 9174 PY of follow-up in the all-brodalumab group, and mean duration of exposure to brodalumab was 23.3 months. In the overall brodalumab $210 \mathrm{mg}$ Q2W group, there were a total of 2543 PY of exposure and a total of $2686 \mathrm{PY}$ of follow-up, and mean duration of exposure was 23.4 months.

Baseline characteristics among patients enrolled in the initial 12-week period, including sex, age, and duration of psoriasis, were similar across all groups (Table 1). Overall, $\sim 70 \%$ of patients were men and $\sim 90 \%$ were White, and most patients $(57 \%)$ were $\geq 40$ to $<65$ years of age. The mean (standard deviation [SD]) duration of psoriasis was $\sim 18.5$ (12.1) years, $21 \%$ of patients had psoriatic arthritis, the mean (SD) PASI score was 20.1 (8.1), and almost all patients $(>99 \%)$ had a static physician's global assessment of psoriasis score of $\geq 3$. At study baseline, $2-3 \%$ of patients across treatment groups reported a history of malignancy (Table 1).

\subsection{Event Rates Through Week 12}

Few malignancy events were reported during the 12-week induction period (Table 2). Within this period, no adjudicated malignancies were reported over a total of $195 \mathrm{PY}$ of exposure in those receiving placebo, one was reported over a total of $140 \mathrm{PY}$ in those receiving ustekinumab, and four were reported over a total of $688 \mathrm{PY}$ among all patients receiving brodalumab. Exposure-adjusted event rates for adjudicated malignancies were similar in the ustekinumab, brodalumab $210 \mathrm{mg} \mathrm{Q} 2 \mathrm{~W}$, and all-brodalumab treatment groups, ranging from 0.6 to 0.7 events per $100 \mathrm{PY}$ of exposure. There were three cases of NMSC among all patients receiving brodalumab and no cases in the placebo or ustekinumab groups. Through week 12, one SEER-adjudicated malignancy (prostate cancer) occurred in a patient receiving ustekinumab, and one (penile squamous cell cancer) occurred among all patients receiving brodalumab. One patient in the brodalumab $140 \mathrm{mg}$ Q2W group had pancreatic carcinoma, a grade 4 serious AE that was reported on study day 39 (after the exposure period); however, this patient received only one dose of brodalumab before being discontinued from the study.

\subsection{Event Rates Through Week 52}

Exposure-adjusted adjudicated malignancy event rates through 52 weeks were lower in the all-brodalumab group

Table 2 Malignancy exposure-adjusted event rates (12-week results)

\begin{tabular}{|c|c|c|c|c|}
\hline & $\begin{array}{l}\text { Placebo } \\
(n=879 ; 195 \mathrm{PY})\end{array}$ & $\begin{array}{l}\text { Ustekinumab } \\
(n=613 ; 140 \mathrm{PY})\end{array}$ & $\begin{array}{l}\text { Brodalumab } \\
210 \mathrm{mg} \mathrm{Q} 2 \mathrm{~W} \\
(n=1496 ; 336 \mathrm{PY})\end{array}$ & $\begin{array}{l}\text { All brodalumab } \\
(n=3066 ; 688 \\
\mathrm{PY})^{\mathrm{a}}\end{array}$ \\
\hline Adjudicated malignancies & 0 & $1(0.7)$ & $2(0.6)$ & $4(0.6)$ \\
\hline NMSC & 0 & 0 & $1(0.3)$ & $3(0.4)$ \\
\hline Basal cell carcinoma & 0 & 0 & 0 & $2(0.3)$ \\
\hline Squamous cell carcinoma & 0 & 0 & $1(0.3)$ & $1(0.1)$ \\
\hline SEER-adjudicated malignancies & 0 & $1(0.7)$ & $1(0.3)$ & $1(0.1)$ \\
\hline Penile squamous cell carcinoma & 0 & 0 & $1(0.3)$ & $1(0.1)$ \\
\hline Prostate cancer & 0 & $1(0.7)$ & 0 & 0 \\
\hline
\end{tabular}

Values are the number of events (exposure-adjusted event rate per 100 patient-years $[n / \mathrm{PY} \times 100]$ )

$N M S C$ nonmelanoma skin cancer, $P Y$ total patient-years of exposure through week 12, $Q 2 W$ every 2 weeks, SEER Surveillance, Epidemiology, and End Results

${ }^{\text {a }}$ The all-brodalumab group includes all patients who received $\geq 1$ dose of brodalumab 
(0.9 events per $100 \mathrm{PY})$ than in the ustekinumab group (2.6 events per 100 PY; Fig. 1). Exposure-adjusted rates of NMSC through 52 weeks were 0.6 events per $100 \mathrm{PY}$ in the all-brodalumab group (basal cell carcinoma [ $n=15], 0.4$ events per $100 \mathrm{PY}$ and squamous cell carcinoma $[n=4]$, 0.1 events per PY) and were 2.2 events per $100 \mathrm{PY}$ in the ustekinumab group (basal cell carcinoma $[n=8], 1.6$ events per PY; squamous cell carcinoma [ $n=2]$, 0.4 events per PY; and Bowen disease [ $n=1], 0.2$ events per PY; Fig. 1). The ratio of basal cell carcinoma to squamous cell carcinoma events was 4:1 in the ustekinumab group and 3.8:1 in the all-brodalumab group. Most malignancy AEs through week 52 were grade $\leq 2$ in severity.

Exposure-emergent serious AEs occurring in more than one patient included adenocarcinoma of the pancreas in two brodalumab-treated patients, basal cell carcinoma in two ustekinumab-treated patients, one case of prostate cancer each for brodalumab and ustekinumab, and two cases of uterine leiomyoma with brodalumab. Two brodalumabtreated patients had grade 4 treatment-emergent serious malignancy AEs, which were bile duct adenocarcinoma and follicle center lymphoma. One fatal malignancy AE, pancreatic carcinoma, occurred in the ustekinumab group.

\subsection{Event Rates Through End of Study}

Rates of malignancy events in brodalumab-treated patients in the long-term analysis (Table 3) were consistent with the 52 -week results. NMSC was experienced by 56 patients in the all-brodalumab group (basal cell carcinoma $[n=39]$ and squamous cell carcinoma $[n=9]$ follow-up time-adjusted NMSC event rate: 0.6 per $100 \mathrm{PY}$ ) and in 11 patients in the brodalumab 210-mg Q2W group (basal cell carcinoma [ $n=7]$ and squamous cell carcinoma $[n=2]$ follow-up time-adjusted NMSC event rate: 0.4 per $100 \mathrm{PY}$ ). A total of 37 SEER-adjudicated malignancies were reported over a total of $9174 \mathrm{PY}$ of exposure; the most common of these was prostate cancer $(n=8 ; 0.1$ events per $100 \mathrm{PY}$ in the all-brodalumab group; Table 3). There was one case of B-cell lymphoma and one case of follicle center lymphoma in the all-brodalumab group.

\subsection{History of Malignancy}

In an exploratory analysis, $2-3 \%$ of patients across treatment groups reported history (typically $>5$ years before screening, with exceptions listed in Methods) of malignancy (Table 1). Among the most common types of prior malignancy were basal cell carcinoma, squamous cell carcinoma, breast cancer, malignant melanoma, squamous cell carcinoma of the skin, thyroid neoplasm, prostate cancer, and uterine cancer (Supplementary Table 1, see Electronic Supplementary Material). Of patients with prior malignancy $(n=138)$, $41-67 \%$ of patients across treatment groups reported previous treatment with any phototherapy (placebo $[n=18]$, 66.7\%; ustekinumab [ $n=17], 41.2 \%$; brodalumab $210 \mathrm{mg}$ Q2W [ $n=34], 55.9 \%$; all-brodalumab group [ $n=69]$, $52.2 \%)$. One patient in the brodalumab $210 \mathrm{mg}$ Q2W group with a history of resolved basal cell carcinoma experienced an adjudicated malignancy event of squamous cell carcinoma during the 12-week induction phase. Overall, three adjudicated malignancies, also classified as NMSC AEs (one basal cell carcinoma, two squamous cell carcinoma), were reported in patients with malignancy history who received constant brodalumab $210 \mathrm{mg}$ Q2W through 52 weeks. The three patients who experienced these NMSC AEs entered the clinical program with a history of resolved breast cancer $(n=1)$, basal cell carcinoma $(n=3)$, and squamous cell carcinoma $(n=1)$.

\section{Discussion}

In clinical studies of brodalumab, rates of malignancy were generally low. In the long-term analysis of 4464 patients receiving brodalumab over 8655 total PY of exposure, the
Fig. 1 Malignancy event rates (52-week results). The all-brodalumab group includes all patients who received $\geq 1$ dose of brodalumab. NMSC nonmelanoma skin cancer, $P Y$ total patient-years of exposure through week $52, Q 2 W$ every 2 weeks, SEER Surveillance, Epidemiology, and End Results

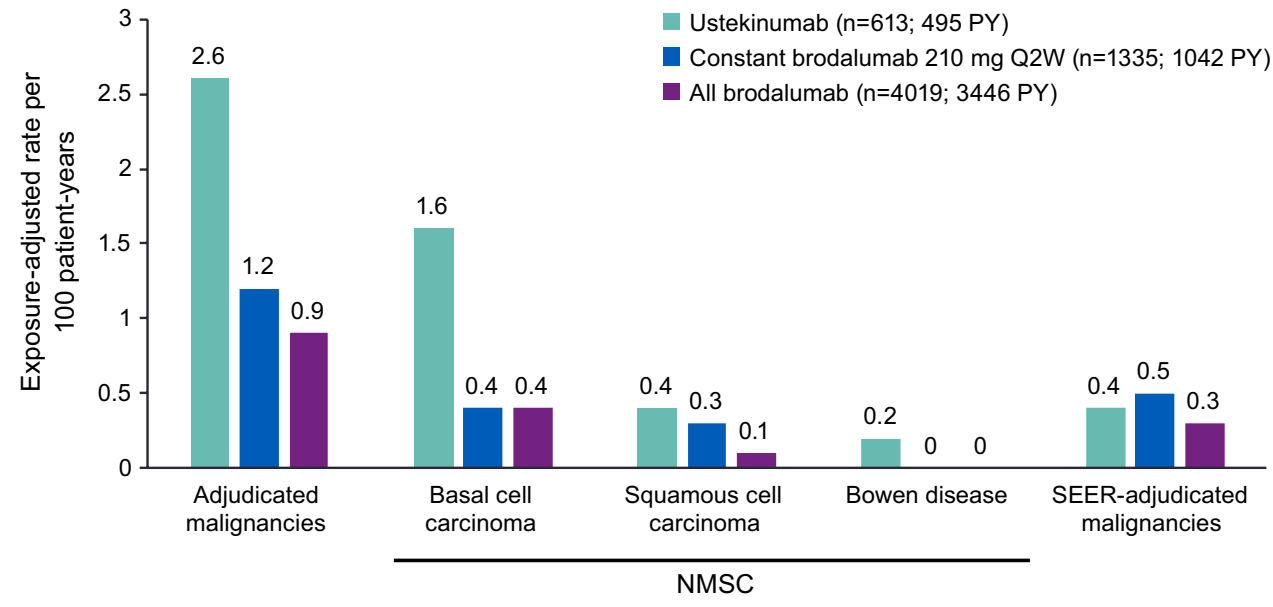


Table 3 Malignancy exposure-adjusted and follow-up observation time-adjusted event rates with brodalumab (long-term pool)

\begin{tabular}{|c|c|c|c|c|}
\hline & \multicolumn{2}{|l|}{$\begin{array}{l}\text { Overall brodalumab } \\
210 \mathrm{mg} \text { Q2W } \\
(n=1304)^{\mathrm{a}}\end{array}$} & \multicolumn{2}{|l|}{$\begin{array}{l}\text { All brodalumab } \\
(n=4464)^{\mathrm{b}}\end{array}$} \\
\hline & $\begin{array}{l}\text { Exposure-adjusted event } \\
\text { rate per } 100 \text { patient-years } \\
(2543 \mathrm{PY})\end{array}$ & $\begin{array}{l}\text { Follow-up time-adjusted } \\
\text { event rate per } 100 \text { patient- } \\
\text { years ( } 2686 \mathrm{PY})\end{array}$ & $\begin{array}{l}\text { Exposure-adjusted event } \\
\text { rate per } 100 \text { patient-years } \\
(8655 \mathrm{PY})\end{array}$ & $\begin{array}{l}\text { Follow-up time-adjusted } \\
\text { event rate per } 100 \text { patient- } \\
\text { years (9174 PY) }\end{array}$ \\
\hline Adjudicated malignancies & $19(0.7)$ & $21(0.8)$ & $82(0.9)$ & $93(1.0)$ \\
\hline NMSC & $11(0.4)$ & $11(0.4)$ & $56(0.6)$ & $56(0.6)$ \\
\hline Basal cell carcinoma & $7(0.3)$ & $7(0.3)$ & $39(0.5)$ & $39(0.4)$ \\
\hline Squamous cell carcinoma & $2(0.1)$ & $2(0.1)$ & $9(0.1)$ & $9(0.1)$ \\
\hline $\begin{array}{l}\text { Squamous cell carcinoma } \\
\text { of the skin }\end{array}$ & $1(<0.1)$ & $1(<0.1)$ & $6(0.1)$ & $6(0.1)$ \\
\hline $\begin{array}{l}\text { Basosquamous carci- } \\
\text { noma of the skin }\end{array}$ & 0 & 0 & $1(<0.1)$ & $1(<0.1)$ \\
\hline $\begin{array}{l}\text { Squamous cell carcinoma } \\
\text { of the oral cavity }\end{array}$ & $1(<0.1)$ & $1(<0.1)$ & $1(<0.1)$ & $1(<0.1)$ \\
\hline $\begin{array}{l}\text { SEER-adjudicated malig- } \\
\text { nancies }\end{array}$ & $8(0.3)$ & $10(0.4)$ & $26(0.3)$ & $37(0.4)$ \\
\hline Prostate cancer & 0 & 0 & $7(0.1)$ & $8(0.1)$ \\
\hline Breast cancer & $1(<0.1)$ & $1(<0.1)$ & $3(<0.1)$ & $3(<0.1)$ \\
\hline $\begin{array}{l}\text { Adenocarcinoma of the } \\
\text { pancreas }\end{array}$ & $1(<0.1)$ & $1(<0.1)$ & $2(<0.1)$ & $2(<0.1)$ \\
\hline $\begin{array}{l}\text { Adenocarcinoma of the } \\
\text { colon }\end{array}$ & 0 & 0 & $1(<0.1)$ & $1(<0.1)$ \\
\hline B-cell lymphoma & 0 & 0 & 0 & $1(<0.1)$ \\
\hline $\begin{array}{l}\text { Bile duct adenocarci- } \\
\text { noma }\end{array}$ & 0 & 0 & $1(<0.1)$ & $1(<0.1)$ \\
\hline Bladder cancer & 0 & $1(<0.1)$ & 0 & $1(<0.1)$ \\
\hline $\begin{array}{l}\text { Bladder transitional cell } \\
\text { carcinoma }\end{array}$ & 0 & 0 & $1(<0.1)$ & $1(<0.1)$ \\
\hline Carcinoid tumor & 0 & 0 & $1(<0.1)$ & $2(<0.1)$ \\
\hline Colon cancer & $1(<0.1)$ & $1(<0.1)$ & $1(<0.1)$ & $1(<0.1)$ \\
\hline Endometrial cancer & 0 & 0 & 0 & $1(<0.1)$ \\
\hline $\begin{array}{l}\text { Esophageal adenocarci- } \\
\text { noma }\end{array}$ & 0 & 0 & 0 & $1(<0.1)$ \\
\hline Esophageal carcinoma & $1(<0.1)$ & $1(<0.1)$ & $1(<0.1)$ & $1(<0.1)$ \\
\hline $\begin{array}{l}\text { Follicle center lym- } \\
\text { phoma, follicular grade } \\
1-3\end{array}$ & 0 & 0 & $1(<0.1)$ & $1(<0.1)$ \\
\hline $\begin{array}{l}\text { Invasive ductal breast } \\
\text { carcinoma }\end{array}$ & $1(<0.1)$ & $1(<0.1)$ & $1(<0.1)$ & $1(<0.1)$ \\
\hline $\begin{array}{l}\text { Malignant anorectal } \\
\text { neoplasm }\end{array}$ & 0 & 0 & 0 & $1(<0.1)$ \\
\hline $\begin{array}{l}\text { Metastases to lymph } \\
\text { nodes }\end{array}$ & 0 & $1(<0.1)$ & 0 & $1(<0.1)$ \\
\hline Pancreatic carcinoma & 0 & 0 & $1(<0.1)$ & $2(<0.1)$ \\
\hline Papillary thyroid cancer & $1(<0.1)$ & $1(<0.1)$ & $1(<0.1)$ & $1(<0.1)$ \\
\hline $\begin{array}{l}\text { Penile squamous cell } \\
\text { carcinoma }\end{array}$ & 0 & 0 & $1(<0.1)$ & $1(<0.1)$ \\
\hline Rectal cancer & $1(<0.1)$ & $1(<0.1)$ & $1(<0.1)$ & $1(<0.1)$ \\
\hline Renal cancer & 0 & 0 & $1(<0.1)$ & $1(<0.1)$ \\
\hline Renal cell carcinoma & 0 & 0 & 0 & $1(<0.1)$ \\
\hline Small cell lung cancer & 0 & 0 & 0 & $1(<0.1)$ \\
\hline
\end{tabular}


Table 3 (continued)

\begin{tabular}{|c|c|c|c|c|}
\hline & \multicolumn{2}{|l|}{$\begin{array}{l}\text { Overall brodalumab } \\
210 \mathrm{mg} \text { Q2W } \\
(n=1304)^{\mathrm{a}}\end{array}$} & \multicolumn{2}{|l|}{$\begin{array}{l}\text { All brodalumab } \\
(n=4464)^{\mathrm{b}}\end{array}$} \\
\hline & $\begin{array}{l}\text { Exposure-adjusted event } \\
\text { rate per } 100 \text { patient-years } \\
(2543 \mathrm{PY})\end{array}$ & $\begin{array}{l}\text { Follow-up time-adjusted } \\
\text { event rate per } 100 \text { patient- } \\
\text { years ( } 2686 \mathrm{PY})\end{array}$ & $\begin{array}{l}\text { Exposure-adjusted event } \\
\text { rate per } 100 \text { patient-years } \\
(8655 \mathrm{PY})\end{array}$ & $\begin{array}{l}\text { Follow-up time-adjusted } \\
\text { event rate per } 100 \text { patient- } \\
\text { years ( } 9174 \text { PY) }\end{array}$ \\
\hline $\begin{array}{l}\text { Small intestine carcinoma } \\
\text { metastatic }\end{array}$ & $1(<0.1)$ & $1(<0.1)$ & $1(<0.1)$ & $1(<0.1)$ \\
\hline
\end{tabular}

Values are the number of events (exposure- or follow-up observation time-adjusted event rate per 100 patient-years [n/PY $\times 100]$ ). The mean (SD) duration of cumulative exposure in the overall brodalumab 210-mg Q2W group was 23.4 (7.9) months and was 23.3 (10.9) months in the all-brodalumab group

NMSC nonmelanoma skin cancer, $P Y$ total patient-years of exposure or follow-up through end of study, $Q 2 W$ every 2 weeks, $S D$ standard deviation, SEER Surveillance, Epidemiology, and End Results

${ }^{\mathrm{a}}$ In the overall brodalumab 210 -mg Q2W group, $\geq 75 \%$ of doses were $210 \mathrm{mg}$ only

${ }^{\mathrm{b}}$ The all-brodalumab group includes all patients who received $\geq 1$ dose of brodalumab

event rate for all malignancies was 0.9 per $100 \mathrm{PY}$, and the event rate for NMSC was 0.6 per 100 PY. Through 52 weeks, the event rate for all malignancies was 2.6 per $100 \mathrm{PY}$ for the active comparator ustekinumab. Three NMSCs were reported in patients with malignancy history receiving constant brodalumab $210 \mathrm{mg}$ Q2W through 52 weeks.

The risk of malignancy among patients receiving treatment for psoriasis has been previously assessed in numerous studies of commonly used treatments, including the anti-TNF $\alpha$ antibodies infliximab and adalimumab, the anti-IL-12/23 p40 antibody ustekinumab, and the anti-IL$17 \mathrm{~A}$ antibodies secukinumab and ixekizumab. Comparison of event rates between studies must be made with caution because there are differences in study setting, inclusion and exclusion criteria (including definition of psoriasis and psoriatic arthritis), design, treatment type and regimen, and methods of defining, determining, and reporting AEs. However, malignancy findings from studies of other psoriasis agents provide context for the current analysis of brodalumab safety.

Malignancy risk with use of anti-IL-12/23 or anti-IL-17 treatment for psoriasis has been investigated in long-term analyses of clinical study data. After 5 years of follow-up of ustekinumab treatment for psoriasis, an analysis of 8998 total PY of follow-up found event rates of 0.64 per $100 \mathrm{PY}$ (45 mg) and 0.44 per $100 \mathrm{PY}(90 \mathrm{mg})$ for NMSC and 0.59 per $100 \mathrm{PY}(45 \mathrm{mg})$ and 0.61 per $100 \mathrm{PY}(90 \mathrm{mg})$ for other malignancies [18]. In an analysis of 2725 total PY of secukinumab exposure over 52 weeks, the event rate was 0.48 per $100 \mathrm{PY}$ for NMSC and also 0.48 per $100 \mathrm{PY}$ for other malignant or unspecified tumors [19]. Over 6480 total PY of ixekizumab exposure over 60 weeks, the incidence rate was 0.4 per $100 \mathrm{PY}$ for NMSC and 0.5 per $100 \mathrm{PY}$ for malignancies excluding NMSC [20]. Finally, over 1373 total PY of ixekizumab exposure in psoriatic arthritis, the incidence rate of malignancy was 0.7 per $100 \mathrm{PY}$ [21]. As stated previously, comparisons between different studies must be made with caution, but rates of malignancy in the current study of brodalumab ( 0.9 events per $100 \mathrm{PY}$ for all malignancies and 0.6 events per $100 \mathrm{PY}$ for NMSC) appear consistent with rates reported for other psoriasis treatments. Three NMSCs were reported over 52 weeks in patients with malignancy history who were treated with brodalumab $210 \mathrm{mg} \mathrm{Q} 2 \mathrm{~W}$. Furthermore, 1-year post-marketing pharmacovigilance monitoring showed three cases of malignancy (hepatic, lung, and ovarian), all considered unrelated to brodalumab [22]. Overall, there is limited clinical evidence that use of biologic treatments for psoriasis increases malignancy risk. The complex role of inflammatory cytokines such as IL-17 in mediating tumor growth, development, and immunity is an active area of clinical and preclinical investigation [23]. Real-world studies are needed to understand any potential long-term malignancy risk with anti-IL-17 biologic treatments for psoriasis.

Several studies have assessed malignancy risk with anti$\mathrm{TNF} \alpha$ therapy. In one registry study among patients with psoriasis, an analysis including 23,660 total PY of adalimumab use found a rate of 1.0 events of malignancy per 100 PY of exposure [24]. In a retrospective cohort study, incidence rates per $100 \mathrm{PY}$ of observation for malignancies excluding NMSC were higher for infliximab (2.30) and lower for adalimumab (0.78) compared with the rate in the overall psoriasis population (1.42). However, for NMSC, incidence rates per $100 \mathrm{PY}$ were lower for infliximab (1.68) and higher for adalimumab (2.41) compared with the psoriasis population (1.80) [25]. A systematic review of adalimumab safety in psoriasis registries found event rates of 0.9 per $100 \mathrm{PY}$ for malignancy, <0.6 per $100 \mathrm{PY}$ for malignancies excluding NMSC, and a range of $<0.5-0.6$ per 100 PY for NMSC [26]. Another systematic review found an increased risk of NMSC, but not other malignancies, among patients with psoriasis treated with anti-TNF $\alpha$ therapy, 
compared with the general population and with patients with rheumatoid arthritis treated with anti-TNF therapy [27].

Multiple studies in disease states other than psoriasis have investigated risk of malignancy, particularly lymphoma, associated with use of anti-TNF $\alpha$ agents [28-31]. These studies found no increase in risk of malignancy compared with patients with the same disease treated with other classes of agents [28-31]. One study of self-reported data among patients with rheumatoid arthritis found a small (hazard ratio, 1.24) but not statistically significant increase in the rate of NMSC with use of anti-TNF $\alpha$ therapy [32]. A systematic review found no evidence of increased risk of overall cancer, lymphoma, or melanoma with use of anti-TNF $\alpha$ therapy across disease states, but findings for NMSC were inconsistent [33]. A prospective cohort study in Sweden showed that patients with rheumatoid arthritis treated with TNF inhibitors had an increased risk of invasive melanoma relative to patients not treated with biologics (hazard ratio, 1.5) [34]. An examination of electronic medical records from an academic medical center identified 35 cases of melanoma among 6045 patients exposed to a TNF $\alpha$ inhibitor [35]. There were also 972 reports of melanoma associated with TNF $\alpha$ inhibitors in the US Food and Drug Administration Adverse Events Reporting System database (from the date of approval for each drug through August 2012) [35]. However, a systematic review found no sufficient evidence to conclude that anti-TNF $\alpha$ agents increase malignancy risk [36].

Among studies that reported findings across multiple drug classes in patients with psoriasis, a network meta-analysis including clinical trials of anti-TNF $\alpha$, anti-IL-12/23, and anti-IL-17 therapies found that malignancies were reported in both the intervention and placebo groups across all of these classes; however, event rates were not reported [14]. In the Psoriasis Longitudinal Assessment Registry, treatment with ustekinumab was not associated with increased malignancy risk compared with no ustekinumab treatment, but treatment for $>12$ months with a TNF $\alpha$ inhibitor (infliximab, adalimumab, or etanercept) was associated with a 1.5 -fold increase in malignancy risk compared with no TNF $\alpha$ inhibitor treatment [37]. In a Psoriasis Longitudinal Assessment and Registry (PSOLAR) analysis of 12,095 patients treated with biologics who were followed up for 31,818 PY, the rate of malignancies excluding NMSC was 0.68 per 100 $\mathrm{PY}$ in the overall group; this rate was lower for patients in the infliximab ( 0.58 per $100 \mathrm{PY})$ or ustekinumab $(0.53$ per $100 \mathrm{PY}$ ) groups [38]. In a later PSOLAR analysis over a total of 40,388 PY of exposure to biologics, the rate of malignancies excluding NMSC remained 0.68 per $100 \mathrm{PY}$ in the overall group; this rate was 0.79 per $100 \mathrm{PY}$ in the infliximab group and 0.48 per $100 \mathrm{PY}$ in the ustekinumab group, possibly indicating increasing incidence of malignancy over time for the anti-TNF $\alpha$ agent infliximab [39].
Further investigations are needed to characterize long-term malignancy risk across these biologic classes.

This study had some limitations. Fewer patients received ustekinumab than those receiving brodalumab, resulting in less exposure to ustekinumab. Patients in the clinical studies received varying doses of brodalumab on varying schedules, which limits the ability to generalize to patients receiving the recommended dose of $210 \mathrm{mg}$ Q2W [9]. Longer follow-up time is needed to understand the potential clinical implications of the ratio of basal cell carcinoma to squamous cell carcinoma (3.8:1 through 52 weeks) in patients who received any dose of brodalumab, and observations such as the occurrence of eight cases of prostate cancer over a total of 9174 PY of follow-up. Follow-up in this analysis continued for only 266 weeks at most, and the mean exposure was $<2$ years in the long-term pool. Increased rates of malignancy beyond this time period could not be assessed.

\section{Conclusions}

In conclusion, on the basis of an analysis of $>8000 \mathrm{PY}$ of exposure, brodalumab appears to have a low carcinogenic risk. Rates of malignancy among brodalumab-treated patients with psoriasis were low in clinical studies. Few events of malignancy occurred in patients with a history of malignancy through 52 weeks. Longer follow-up and realworld evidence are needed to characterize the long-term risk of malignancy with brodalumab.

Acknowledgments Medical writing assistance was provided under the direction of the authors by Lisa Baker, $\mathrm{PhD}$, Rebecca Slager, $\mathrm{PhD}$, and David Boffa, ELS, of MedThink SciCom, with support from Ortho Dermatologics. Ortho Dermatologics is a division of Bausch Health US, LLC. Some results of this study were previously presented at the Fall Clinical Dermatology Conference, October 18-21, 2018, Las Vegas, NV; the Orlando Dermatology Aesthetic \& Clinical Conference, January 18-21, 2019, Orlando, FL; the 43rd Annual Hawaii Dermatology Seminar, February 17-22, 2019, The Big Island, HI; and the 2020 Winter Clinical Dermatology Conference; January 17-22, 2020; Kohala Coast, HI.

Data Availability The data that support the findings of this study are available from the corresponding author upon reasonable request.

\section{Compliance with Ethical Standards}

Funding/support This analysis was sponsored by Ortho Dermatologics (a division of Bausch Health US, LLC). The AMAGINE-1-2/-3 studies were sponsored by Amgen Inc. Open Access of this article was funded by Ortho Dermatologics (a division of Bausch Health US, LLC).

Ethical approval Study protocols were in compliance with federal regulations and the International Conference on Harmonisation Tripartite Guideline on Good Clinical Practice and were approved by individual institutional review boards at each participating study center. All participants signed and personally dated the informed consent form approved 
by the independent ethics committees and institutional review boards before any study-specific procedures were performed.

Conflicts of interest and financial disclosures Alice Gottlieb has served as a consultant or as an advisory board member for Janssen, Celgene, Bausch Health, Bristol-Myers Squibb, Beiersdorf, AbbVie, UCB, Novartis, Incyte, Eli Lilly, Dr. Reddy's Laboratories, Dermira, Allergan, Sun Pharma, XBiotech, LEO Pharmaceuticals, Avotres Therapeutics, and Boehringer Ingelheim and has received research or educational grants from Janssen, Incyte, Novartis, XBiotech, UCB, and Boehringer Ingelheim. Mark Lebwohl is an employee of Mount Sinai, which receives research funds from AbbVie, Amgen, Arcutis, AstraZeneca, Boehringer Ingelheim, Celgene, Clinuvel, Eli Lilly, Incyte, Janssen Research \& Development, LLC, Kadmon Corp., LLC, LEO Pharmaceuticals, Medimmune, Novartis, Ortho Dermatologics, Pfizer, Sciderm, UCB, Inc., and ViDac and has been a consultant for Allergan, Almirall, Arcutis, Inc., Avotres Therapeutics, BirchBioMed Inc., Boehringer Ingelheim, Bristol-Myers Squibb, Cara Therapeutics, Castle Biosciences, Corrona, Dermavant Sciences, Evelo, Foundation for Research and Education in Dermatology, Inozyme Pharma, LEO Pharmaceuticals, Meiji Seika Pharma, Menlo, Mitsubishi, Neuroderm, Pfizer, Promius/Dr. Reddy's Laboratories, Theravance, and Verrica. Clive Liu has served on speaker bureaus and participated in research and advisory boards for AbbVie, Celgene, Novartis, Lilly, Regeneron, Sanofi, Sun Pharma, Ortho Dermatologics, and Janssen. Robert J. Israel is an employee of Bausch Health US, LLC (an affiliate of Bausch Health Companies Inc.) and holds stock and/or stock options in the company. Abby Jacobson is an employee of Ortho Dermatologics (a division of Bausch Health US, LLC) and holds stocks and/or stock options in Bausch Health.

Open Access This article is licensed under a Creative Commons Attribution-NonCommercial 4.0 International License, which permits any non-commercial use, sharing, adaptation, distribution and reproduction in any medium or format, as long as you give appropriate credit to the original author(s) and the source, provide a link to the Creative Commons licence, and indicate if changes were made. The images or other third party material in this article are included in the article's Creative Commons licence, unless indicated otherwise in a credit line to the material. If material is not included in the article's Creative Commons licence and your intended use is not permitted by statutory regulation or exceeds the permitted use, you will need to obtain permission directly from the copyright holder.To view a copy of this licence, visit http://creativecommons.org/licenses/by-nc/4.0/.

\section{References}

1. Brauchli YB, Jick SS, Miret M, Meier CR. Psoriasis and risk of incident cancer: an inception cohort study with a nested casecontrol analysis. J Invest Dermatol. 2009;129(11):2604-12.

2. Pouplard C, Brenaut E, Horreau C, Barnetche T, Misery L, Richard MA, et al. Risk of cancer in psoriasis: a systematic review and meta-analysis of epidemiological studies. J Eur Acad Dermatol Venereol. 2013;27(suppl 3):36-46.

3. Kimball AB, Gladman D, Gelfand JM, Gordon K, Horn EJ, Korman NJ, et al. National Psoriasis Foundation clinical consensus on psoriasis comorbidities and recommendations for screening. $\mathrm{J}$ Am Acad Dermatol. 2008;58(6):1031-42.

4. Paul CF, Ho VC, McGeown C, Christophers E, Schmidtmann B, Guillaume JC, et al. Risk of malignancies in psoriasis patients treated with cyclosporine: a 5 y cohort study. J Invest Dermatol. 2003;120(2):211-6.
5. Geller S, Xu H, Lebwohl M, Nardone B, Lacouture ME, Kheterpal $M$. Malignancy risk and recurrence with psoriasis and its treatments: a concise update. Am J Clin Dermatol. 2018;19(3):363-75.

6. Kaushik SB, Lebwohl MG. Psoriasis: which therapy for which patient: psoriasis comorbidities and preferred systemic agents. J Am Acad Dermatol. 2019;80(1):27-40.

7. Ngiow SF, Teng MW, Smyth MJ. A balance of interleukin-12 and -23 in cancer. Trends Immunol. 2013;34(11):548-55.

8. Teng MW, Vesely MD, Duret H, McLaughlin N, Towne JE, Schreiber RD, et al. Opposing roles for IL-23 and IL-12 in maintaining occult cancer in an equilibrium state. Cancer Res. 2012;72(16):3987-96.

9. Siliq [package insert]. Bridgewater, NJ: Valeant Pharmaceuticals North America, LLC; 2017.

10. Lebwohl M, Strober B, Menter A, Gordon K, Weglowska J, Puig $\mathrm{L}$, et al. Phase 3 studies comparing brodalumab with ustekinumab in psoriasis. N Engl J Med. 2015;373(14):1318-28.

11. Papp KA, Reich K, Paul C, Blauvelt A, Baran W, Bolduc C, et al. A prospective phase III, randomized, double-blind, placebo-controlled study of brodalumab in patients with moderate-to-severe plaque psoriasis. Br J Dermatol. 2016;175(2):273-86.

12. Roman M, Chiu MW. Spotlight on brodalumab in the treatment of moderate-to-severe plaque psoriasis: design, development, and potential place in therapy. Drug Des Devel Ther. 2017;11:2065-75.

13. Tong Y, Peranteau AJ, Nawas Z, Tyring SK. A review of brodalumab, an IL-17 receptor antagonist, for moderate-to-severe plaque psoriasis. Skin Therapy Lett. 2017;22(1):1-6.

14. Sbidian E, Chaimani A, Garcia-Doval I, Do G, Hua C, Mazaud $\mathrm{C}$, et al. Systemic pharmacological treatments for chronic plaque psoriasis: a network meta-analysis. Cochrane Database Syst Rev. 2017;12:CD011535.

15. Papp KA, Leonardi C, Menter A, Ortonne JP, Krueger JG, Kricorian G, et al. Brodalumab, an anti-interleukin-17-receptor antibody for psoriasis. N Engl J Med. 2012;366(13):1181-9.

16. Papp K, Leonardi C, Menter A, Thompson EH, Milmont CE, Kricorian G, et al. Safety and efficacy of brodalumab for psoriasis after 120 weeks of treatment. J Am Acad Dermatol. 2014;71(6):1183-90 e3.

17. National Cancer Institute. Surveillance, Epidemiology, and End Results Program 2019. https://seer.cancer.gov/. Accessed 29 October 2019.

18. Papp KA, Griffiths CE, Gordon K, Lebwohl M, Szapary PO, Wasfi $Y$, et al. Long-term safety of ustekinumab in patients with moderate-to-severe psoriasis: final results from 5 years of followup. Br J Dermatol. 2013;168(4):844-54.

19. van de Kerkhof PC, Griffiths CE, Reich K, Leonardi CL, Blauvelt A, Tsai TF, et al. Secukinumab long-term safety experience: a pooled analysis of 10 phase II and III clinical studies in patients with moderate to severe plaque psoriasis. J Am Acad Dermatol. 2016;75(1):83-98 e4.

20. Strober B, Leonardi C, Papp KA, Mrowietz U, Ohtsuki M, Bissonnette R, et al. Short- and long-term safety outcomes with ixekizumab from 7 clinical trials in psoriasis: etanercept comparisons and integrated data. J Am Acad Dermatol. 2017;76(3):432-40 e17.

21. Mease P, Roussou E, Burmester GR, Goupille P, Gottlieb A, Moriarty SR, et al. Safety of ixekizumab in patients with psoriatic arthritis: results from a pooled analysis of three clinical trials. Arthritis Care Res (Hoboken). 2019;71(3):367-78.

22. Lebwohl M, Leonardi C, Wu JJ, et al. One-year pharmacovigilance update of brodalumab. Poster presented at: 20th Annual Las Vegas Dermatology Seminar; November 7-9, 2019; Las Vegas, NV.

23. Blake SJ, Teng MW. Role of IL-17 and IL-22 in autoimmunity and cancer. Actas Dermosifiliogr. 2014;105(suppl 1):41-50. 
24. Menter A, Thaci D, Wu JJ, Abramovits W, Kerdel F, Arikan D, et al. Long-term safety and effectiveness of adalimumab for moderate to severe psoriasis: results from 7-year interim analysis of the ESPRIT registry. Dermatol Ther (Heidelb). 2017;7(3):365-81.

25. Kimball AB, Schenfeld J, Accortt NA, Anthony MS, Rothman KJ, Pariser D. Cohort study of malignancies and hospitalized infectious events in treated and untreated patients with psoriasis and a general population in the United States. Br J Dermatol. 2015;173(5):1183-90.

26. Strober B, Crowley J, Langley RG, Gordon K, Menter A, Leonardi $\mathrm{C}$, et al. Systematic review of the real-world evidence of adalimumab safety in psoriasis registries. J Eur Acad Dermatol Venereol. 2018;32(12):2126-33.

27. Peleva E, Exton LS, Kelley K, Kleyn CE, Mason KJ, Smith CH. Risk of cancer in patients with psoriasis on biological therapies: a systematic review. Br J Dermatol. 2018;178(1):103-13.

28. D'Haens G, Reinisch W, Colombel JF, Panes J, Ghosh S, Prantera C, et al. Five-year safety data from ENCORE, a European observational safety registry for adults with Crohn's disease Treated with infliximab [Remicade(R)] or conventional therapy. J Crohns Colitis. 2017;11(6):680-9.

29. D'Haens G, Reinisch W, Panaccione R, Satsangi J, Petersson $\mathrm{J}$, Bereswill M, et al. Lymphoma risk and overall safety profile of adalimumab in patients with Crohn's disease with up to 6 years of follow-up in the pyramid registry. Am J Gastroenterol. 2018;113(6):872-82.

30. Hellgren K, Dreyer L, Arkema EV, Glintborg B, Jacobsson LT, Kristensen LE, et al. Cancer risk in patients with spondyloarthritis treated with TNF inhibitors: a collaborative study from the ARTIS and DANBIO registers. Ann Rheum Dis. 2017;76(1):105-11.

31. Mercer LK, Galloway JB, Lunt M, Davies R, Low AL, Dixon WG, et al. Risk of lymphoma in patients exposed to antitumour necrosis factor therapy: results from the British Society for Rheumatology Biologics Register for Rheumatoid Arthritis. Ann Rheum Dis. 2017;76(3):497-503.
32. Chakravarty EF, Michaud K, Wolfe F. Skin cancer, rheumatoid arthritis, and tumor necrosis factor inhibitors. J Rheumatol. 2005;32(11):2130-5.

33. Chen Y, Friedman M, Liu G, Deodhar A, Chu CQ. Do tumor necrosis factor inhibitors increase cancer risk in patients with chronic immune-mediated inflammatory disorders? Cytokine. 2018:101:78-88.

34. Raaschou P, Simard JF, Holmqvist M, Askling J, Group AS. Rheumatoid arthritis, anti-tumour necrosis factor therapy, and risk of malignant melanoma: nationwide population based prospective cohort study from Sweden. BMJ. 2013;346:f1939.

35. Nardone B, Hammel JA, Raisch DW, Weaver LL, Schneider D, West DP. Melanoma associated with tumour necrosis factor-alpha inhibitors: a Research on Adverse Drug events And Reports (RADAR) project. Br J Dermatol. 2014;170(5):1170-2.

36. Chen Y, Sun J, Yang Y, Huang Y, Liu G. Malignancy risk of antitumor necrosis factor alpha blockers: an overview of systematic reviews and meta-analyses. Clin Rheumatol. 2016;35(1):1-18.

37. Fiorentino D, Ho V, Lebwohl MG, Leite L, Hopkins L, Galindo $\mathrm{C}$, et al. Risk of malignancy with systemic psoriasis treatment in the Psoriasis Longitudinal Assessment Registry. J Am Acad Dermatol. 2017;77(5):845-54

38. Gottlieb AB, Kalb RE, Langley RG, Krueger GG, de Jong EM, Guenther L, et al. Safety observations in 12095 patients with psoriasis enrolled in an international registry (PSOLAR): experience with infliximab and other systemic and biologic therapies. J Drugs Dermatol. 2014;13(12):1441-8.

39. Papp K, Gottlieb AB, Naldi L, Pariser D, Ho V, Goyal K, et al. Safety surveillance for ustekinumab and other psoriasis treatments from the Psoriasis Longitudinal Assessment and Registry (PSOLAR). J Drugs Dermatol. 2015;14(7):706-14. 